\title{
Heritability of Lung Function in Severe Alpha-1 Antitrypsin Deficiency
}

\author{
D.L. DeMeo ${ }^{a}$ E.J. Campbell ${ }^{b}$ M.L. Brantly ${ }^{c} \quad$ A.F. Barker ${ }^{d} \quad$ E. Eden ${ }^{e}$ \\ N.G. McElvaney ${ }^{k}$ S.I. Rennard ${ }^{f} \quad$ J.M. Stocks ${ }^{g} \quad$ J.K. Stoller ${ }^{\text {h }} \quad$ C. Strange ${ }^{i}$ \\ G. Turino $^{\mathrm{e}}$ R.A. Sandhaus ${ }^{j}$ E.K. Silverman ${ }^{a}$ \\ ${ }^{a}$ Channing Laboratory and Division of Pulmonary and Critical Care Medicine, Brigham and Women's Hospital, and \\ Harvard Medical School, Boston, Mass., ' University of Utah, Salt Lake City, Utah, 'University of Florida, Gainesville, \\ Fla., ${ }^{d}$ Oregon Health and Science University, Portland, Oreg., 'St. Luke's/Roosevelt Hospital, New York City, N.Y.,

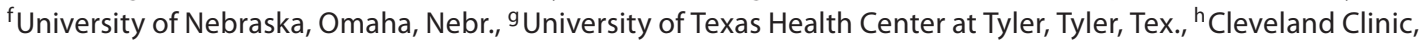 \\ Cleveland, Ohio, ' Medical University of South Carolina, Charleston, S.C., ${ }^{j}$ National Jewish Medical and Research \\ Center, Denver, Colo., USA, ${ }^{k}$ Beaumont Hospital, Dublin, Ireland
}

\section{Key Words}

Familial aggregation • Alpha-1 antitrypsin deficiency • Heritability $\cdot$ Modifier genes

\begin{abstract}
Severe alpha-1 antitrypsin (AAT) deficiency is a proven genetic risk factor for COPD, but there is marked variation in the development of COPD among AAT deficient subjects. To investigate familial aggregation of lung function in subjects with AAT deficiency, we estimated heritability for forced expiratory volume in $1 \mathrm{~s}\left(\mathrm{FEV}_{1}\right)$ and $\mathrm{FEV}_{1} /$ forced vital capacity (FVC) in 378 AAT deficient subjects from 167 families in the AAT Genetic Modifiers Study; all subjects were verified homozygous for the Z AAT deficiency allele. Heritability was evaluated for models that included and excluded an ascertainment correction, as well as for models that excluded, included and were stratified by a cigarette smoking covariate. In models without an ascertainment correction, and in all models without a covariate for smoking, no evidence for familial aggregation of lung function was observed. In models conditioned on the index proband with covariates for smoking, post-bronchodilator $\mathrm{FEV}_{1} / \mathrm{FVC}$ demonstrated significant heritability $(0.26 \pm 0.14, p=0.03)$. When we limited
\end{abstract}

the analysis to subjects with a smoking history, post-bronchodilator $\mathrm{FEV}_{1}$ demonstrated significant heritability $(0.47$ $\pm 0.21, p=0.02)$. Severity rate phenotypes were also assessed as potential phenotypes for genetic modifier studies. Significant heritability was found with all age-of-onset threshold models that included smoking and ascertainment adjustments. Using the t-distribution, the heritability estimates ranged from 0.43 to 0.64 , depending on the ageof-onset of $\mathrm{FEV}_{1}$ decline used for the severity rate calculation. Correction for ascertainment and consideration of gene-by-smoking interactions will be crucial for the identification of genes that may modify susceptibility for COPD in families with AAT deficiency.

Copyright $\odot 2008$ S. Karger AG, Basel

\section{Background}

Chronic obstructive pulmonary disease (COPD) is the fourth leading cause of death in the United States. Alpha1 antitrypsin (AAT) deficiency (OMIM 107400), an autosomal recessive disorder resulting from a mutation in the SERPINA1 gene, is a recognized genetic cause of COPD. Affected individuals are at high risk to develop severe

Dawn L. DeMeo, MD, MPH

Brigham \& Women's Hospital, Channing Laboratory, 181 Longwood Avenue Boston, MA 02115 (USA)

Tel. +1 617525 0866, Fax +1 6175250958

E-Mail dawn.demeo@channing.harvard.edu 
early-onset COPD, especially in the setting of cigarette smoking. AAT deficiency is a proven mendelian cause of COPD, but there is substantial variability in the development of disease among individuals homozygous for the $\mathrm{Z}$ allele; this variability is likely influenced by environmental and other genetic factors.

Spirometric measures of lung function are quantitative phenotypes commonly evaluated in genetic studies of COPD. Many studies have assessed familial aggregation of lung function in general population samples and in cohorts of subjects with COPD, but data on familial aggregation of lung function have been limited in individuals with severe AAT deficiency. In the Boston EarlyOnset COPD Study, heritability estimates for $\mathrm{FEV}_{1}$ were 0.35 [Silverman et al., 2002], conveying the importance of a genetic effect on lung function in families susceptible to severe, early-onset lung disease but without AAT deficiency. In that study, cigarette smoking was a highly significant covariate [Silverman et al., 2002], highlighting the importance of considering gene-by-smoking interactions in heritability estimates and in linkage studies [DeMeo et al., 2004] of intermediate phenotypes of COPD.

Heritability measures of lung function in AAT deficiency provide insight into the potential contribution of modifier genes to health and disease. In this study, we estimated the heritability of lung function measures and severity rate phenotypes, defined as point estimates of lung function decline, in 378 AAT deficiency subjects from 167 families; all individuals were verified to be homozygous for the alpha- 1 antitrypsin deficiency $\mathrm{Z}$ mutation (PI ZZ). We hypothesized that airflow obstruction would demonstrate significant heritability among PI ZZ individuals, suggesting additional modifying genetic effects beyond the protease inhibitor (PI) locus.

\section{Methods}

\section{Cohort and Phenotype Definition}

The AAT Genetic Modifiers Study is a multi-center collaborative project designed to investigate the genetic epidemiology of lung disease in individuals homozygous for the $\mathrm{Z}$ alpha-1 antitrypsin deficiency allele. The study protocol was reviewed by the Institutional Review Boards at each center. Three hundred and seventy eight PI ZZ subjects at least 30 years of age in 167 families were enrolled, and they completed questionnaires, spirometry and blood sample collection as previously described [Demeo et al., 2007b]. Pack-years of cigarette smoking were calculated by multiplying the number of years smoked by the average number of daily cigarettes smoked, divided by 20 . All AAT PI ZZ phenotypes for these 378 individuals were confirmed, as previously described [Demeo et al., 2007b].

Lung Function Heritability in AAT Deficiency
Spirometric measures were obtained using a standardized protocol with the Jaeger Masterscope PC Spirometer system (Jaeger, Hoechberg, Germany). Sixteen subjects had already undergone lung transplantation and/or lung volume reduction surgery at the time of the interview; for these individuals we obtained spirometry results that antedated the surgical procedure. For all individuals, the age used in analyses was the age at spirometry testing. Pre- and post-bronchodilator study spirometry was performed according to American Thoracic Society standards [1995]. Percent predicted values for $\mathrm{FEV}_{1}$ were calculated using equations of Crapo et al. [1981] for Caucasian subjects.

PI ZZ individuals often have accelerated decline in pulmonary function [Seersholm et al., 1995], which is not adequately captured by percent predicted values from the general population. Thus, a 30 year old PI ZZ individual with $\mathrm{FEV}_{1} 90 \%$ of predicted may carry modifier genes for a severe disease course but is not old enough to express the disease trait. On the other hand, an 80 year old PI ZZ individual with $\mathrm{FEV}_{1} 52 \%$ of predicted may carry protective modifier genes which allowed him to survive to an advanced age with only moderate airflow obstruction. In an attempt to capture these age-of-onset effects in the absence of longitudinal data in our dataset, severity rate phenotypes, calculated as point estimates of the rate of lung function decline for this cross-sectional study, were created using the following formula: (Maximum $\mathrm{FEV}_{1} \%$ predicted - Current $\mathrm{FEV}_{1} \%$ predicted)/(Current age - Age threshold for the Initiation of $\mathrm{FEV}_{1}$ decline). The maximum $\mathrm{FEV}_{1} \%$ predicted is not known for each individual; in order to include only positive values, the maximum observed $\mathrm{FEV}_{1}$ $\%$ predicted in our cohort ( $140 \%$ predicted) was used in the numerator for all subjects. The age of initiation of $\mathrm{FEV}_{1}$ decline is also unknown in this cohort, but Piitulainen and colleagues have demonstrated that PI $\mathrm{Z}$ individuals typically have normal $\mathrm{FEV}_{1}$ values at least until age 30 [Bernspang et al., 2007]. Thus, we selected ages 20,25, and 30 as age thresholds for the initiation of $\mathrm{FEV}_{1}$ decline. For example, for the 20 year old threshold, the severity rate phenotype was calculated as: $(140$ - post-bronchodilator $\mathrm{FEV}_{1} \%$ predicted)/(Current age - 20).

\section{Ascertainment Scheme}

The ascertainment of sibling pairs was based on confirmation of homozygosity for the $\mathrm{Z}$ allele at the SERPINA 1 locus. The index case was designated as the first person diagnosed in the family with AAT deficiency regardless of the presence of lung or liver disease. Index cases were not included for 27 families due to death or non-participation of that individual.

\section{Statistical Analysis}

General statistical computations were performed using the SAS package (SAS Statistical Institute, Cary, N.C., USA) running on a SUN server in a UNIX environment. Means and standard deviations were calculated for normally distributed variables, with medians and inter-quartile ranges calculated for non-normally distributed variables. Narrow sense heritability estimates $\left(h^{2}\right)$ were calculated for raw spirometry outcomes using a variance component approach as implemented in the Sequential Oligogenic Linkage Analysis Routines (SOLAR) program [Almasy and Blangero, 1998]. Narrow sense heritability (calculated as the ratio of the phenotypic variance due to the additive genetic effect divided by the total trait phenotypic variance) was estimated for models that included and excluded an ascertainment correction 
Table 1. General demographics of 378 PI ZZ individuals

\begin{tabular}{|c|c|c|c|c|}
\hline & Index & Non-index & $\begin{array}{l}\text { Index smokers } \\
\text { only }\end{array}$ & $\begin{array}{l}\text { Non-index } \\
\text { smokers only }\end{array}$ \\
\hline $\mathrm{n}$ & 140 & 238 & 105 & 128 \\
\hline Sex, F/M & $73 / 67$ & $132 / 106$ & $54 / 51$ & $65 / 63$ \\
\hline Ever-smoker ${ }^{\mathrm{a}}$ & $105(75 \%)$ & $128(54 \%)$ & - & - \\
\hline On augmentation $^{\mathrm{a}}$ & $105(76 \%)$ & $73(31 \%)$ & $88(84 \%)$ & $60(47 \%)$ \\
\hline Age, SD & $52.9 \pm 9.5$ & $51.7 \pm 9.8$ & $50.9 \pm 8.1$ & $50.2(8.4)$ \\
\hline Range & $35.5-74.1$ & $33.3-79.8$ & $35.5-73.1$ & $34.9-70.8$ \\
\hline Pre-bronchodilator $\mathrm{FEV}_{1} \%$ predicted, $\mathrm{SD}^{\mathrm{a}}$ & $46.0 \pm 28.1$ & $72.3 \pm 32.7$ & $39.7 \pm 25.5$ & $60.8 \pm 34.2$ \\
\hline Range & $8.2-116.9$ & $8.9-133.4$ & $8.2-116.9$ & $8.9-133.4$ \\
\hline Post-bronchodilator $\mathrm{FEV}_{1} \%$ predicted, $\mathrm{SD}^{\mathrm{a}}$ & $49.0 \pm 28.5$ & $75.4 \pm 32.3$ & $42.7 \pm 25.9$ & $63.8 \pm 33.6$ \\
\hline Range & $10.7-120.2$ & $12.2-139.6$ & $10.7-120.0$ & $12.2-135.6$ \\
\hline $\mathrm{FEV}_{1} / \mathrm{FVC}, \mathrm{SD}^{\mathrm{a}}$ & $0.43 \pm 0.17$ & $0.60 \pm 0.19$ & $0.40 \pm 0.15$ & $0.53 \pm 0.19$ \\
\hline Range & $0.17-0.91$ & $0.17-1.00$ & $0.17-0.91$ & $0.17-1.00$ \\
\hline Post-bronchodilator $\mathrm{FEV}_{1} / \mathrm{FVC}, \mathrm{SD}^{\mathrm{a}}$ & $0.44 \pm 0.17$ & $0.61 \pm 0.20$ & $0.40 \pm 0.15$ & $0.54 \pm 0.20$ \\
\hline Range & $0.17-0.86$ & $0.18-0.92$ & $0.17-0.86$ & $0.18-0.90$ \\
\hline Pack-years ${ }^{b}$ & $15.4(16.5)$ & $8.8(12.4)$ & $20.6(16.1)$ & $16.3(12.9)$ \\
\hline Range & $0-80.5$ & $0-62$ & $0.3-80.5$ & $0.2-62$ \\
\hline
\end{tabular}

${ }^{a}$ For both the comparisons of index versus non-index subjects and index smokers-only versus non-index smokers only $\mathrm{p}<0.0001$ for the indicated phenotypes.

${ }^{\mathrm{b}}$ For index versus non-index $\mathrm{p}=0.02$ and for index smokers-only versus non-index smokers only $\mathrm{p}=0.03$.

for the index proband, as well as for models that excluded, included and were stratified by a smoking covariate. With regard to cigarette smoking, three models were considered: (1) a model excluding any covariates for cigarette smoking; (2) a model with covariates for pack-years of cigarettes and (pack-years) ${ }^{2}$, and (3) a smokers-only model with the inclusion of pack-years and (packyears) ${ }^{2}$ of cigarette smoking as covariates. Other covariates in all of the models for spirometric phenotypes included age, sex and height. The heritability of the severity rate phenotypes were calculated with adjustment for the effects of smoking (pack-years of cigarettes and (pack-years) ${ }^{2}$ ) and sex, and included an ascertainment correction for the index proband.

\section{Results}

\section{Study Population}

General demographics of the 378 PI ZZ individuals are presented parsed by index case status (table 1). These 378 subjects represent 167 families, with 372 PI ZZ siblings, 3 PI ZZ adult children in families included in the study through a sibling pair, and $1 \mathrm{PI}$ ZZ uncle of PI ZZ siblings. The number of subjects reporting a history of cigarette smoking was higher amongst the index probands ( 75 versus $54 \%, p<0.0001$ ). Forty-eight percent of the overall cohort reported a history of ever receiving alpha-1 antitrypsin augmentation therapy. Although the mean pre- and post-bronchodilator $\mathrm{FEV}_{1}$ values were lower in index probands compared to the non-index subjects $(46.0 \%$ predicted \pm 28.1 versus $72.3 \%$ predicted $\pm 32.7, \mathrm{p}<0.0001$ for pre-bronchodilator, $49.0 \%$ predicted \pm 28.5 versus $75.4 \%$ predicted $\pm 32.3, p<0.0001$ for post-bronchodilator), the ranges for spirometric values were similar (table 1). Although index cases had higher mean pack-years of smoking, there were too few current smokers in the overall cohort (13 total, 1 index, 12 nonindex cases) to model the effects of current smoking in our heritability models. More detailed demographic differences between index and non-index subjects in this cohort have been published previously [Demeo et al., 2007b].

To assess whether the spirometric measures of the index probands were predictive of the spirometric measures of ZZ relatives if no adjustments for cigarette smoking were included, we plotted data for the index proband versus relative values for both post-bronchodilator $\mathrm{FEV}_{1}$ percent predicted and post-bronchodilator $\mathrm{FEV}_{1} / \mathrm{FVC}$ (fig. 1). There was no overall trend for a proband's spirometric values to predict a relative's value without covariate adjustment.

\section{Heritability of Spirometric Measures}

We subsequently calculated heritability estimates for spirometric measures using variance component models 


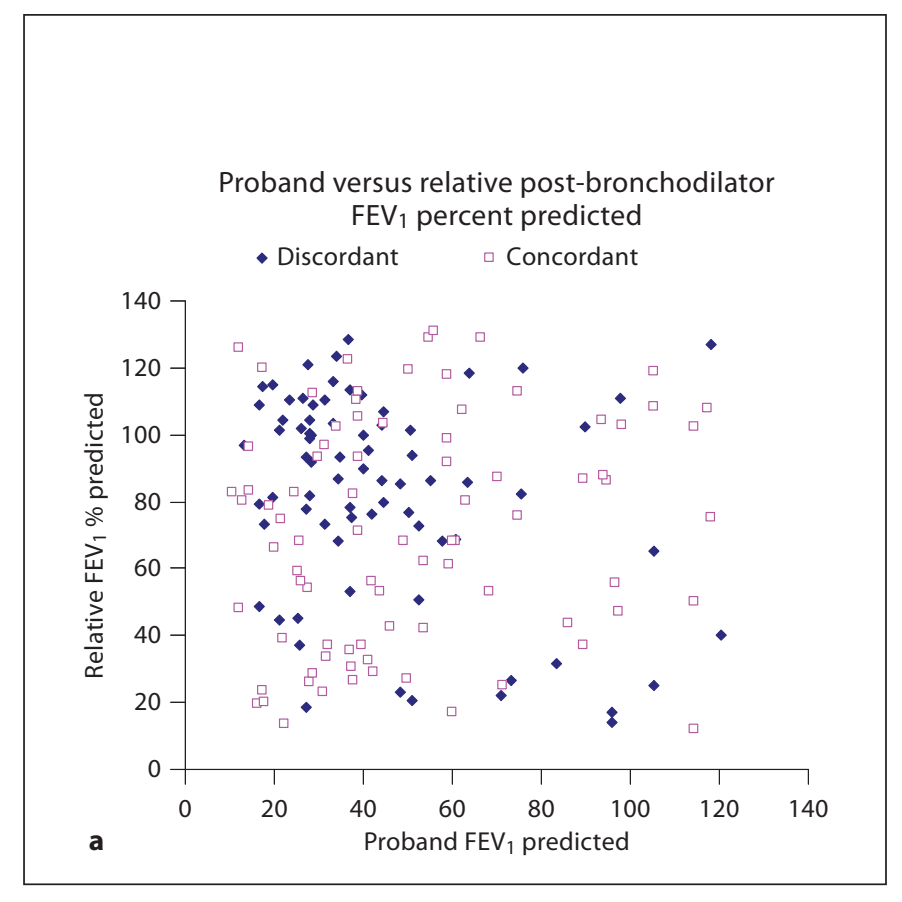

Fig. 1. These figures present a comparison of proband and relative post-bronchodilator $\mathrm{FEV}_{1}(\mathbf{a})$ and $\mathrm{FEV}_{1} / \mathrm{FVC}(\mathbf{b})$. Each relative pair is represented on the figure as a point. The designation of 'Concordant' means that the relative pair shares the same smoking history (either both with a history of cigarette smoking or both

that incorporated an ascertainment correction for the index proband as well as covariates for smoking and sex. An index proband was not designated for 27 families. Models that included an ascertainment correction but excluded smoking covariates revealed heritability estimates of zero for spirometric measures (table 2), consistent with the observed lack of correlation between proband and relative airflow obstruction phenotypes. Models that included the pack-years of smoking covariate as well as ascertainment correction resulted in a significant heritability for both pre- and post-bronchodilator $\mathrm{FEV}_{1} /$ FVC (table 2), while models that included smokers only demonstrated significant heritability estimates for preand post-bronchodilator $\mathrm{FEV}_{1}$, but not for the $\mathrm{FEV}_{1} / \mathrm{FVC}$ ratio. Post-bronchodilator $\mathrm{FEV}_{1}$ in the smokers-only model with ascertainment correction demonstrated the highest overall heritability $(0.47 \pm 0.21, \mathrm{p}=0.02)$.

We subsequently examined familial aggregation for spirometric measures using variance component models that did not include an ascertainment correction (table 2). In models that did not include any smoking covariates, the heritability for both $\mathrm{FEV}_{1}$ and $\mathrm{FEV}_{1} / \mathrm{FVC}$ was 0 . Although the addition of pack-years of smoking to the mod-

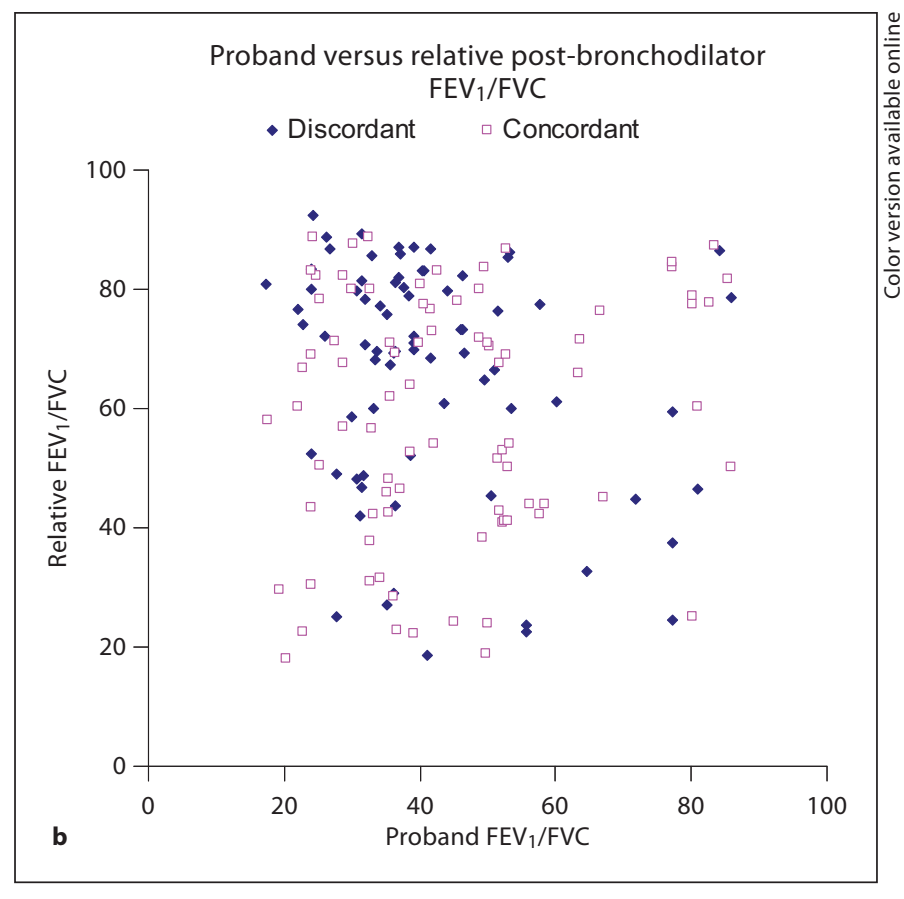

without a history of cigarette smoking). The designation of 'Discordant' means that only one subject in the proband-relative pair reported a history of cigarette smoking. Unadjusted for other covariates, the proband $\mathrm{FEV}_{1}$ and $\mathrm{FEV}_{1} / \mathrm{FVC}$ are not predictive of the relative's values.

els increased the heritability estimates, in the absence of an ascertainment correction, these estimates were not statistically significant for either the overall model with pack-years or the smokers-only models. The inclusion of augmentation therapy in the models did not impact heritability estimates, so this covariate was not included in final models.

\section{Heritability of Point Estimates of FEV $V_{1}$ Decline}

Since PI ZZ subjects often have early-onset COPD and reduced survival, limiting phenotypic assessment to standard measures of airflow obstruction may impair the detection of genetic modifier effects. Therefore, we analyzed severity rate phenotypes using ages 20, 25, and 30 as the ages-of-onset of $\mathrm{FEV}_{1}$ decline. Heritability estimates were calculated with covariates for pack-years of smoking, pack-years ${ }^{2}$, and sex (table 3). Because these severity rate phenotypes had elevated kurtosis values (1.3 for 20 year threshold, 2.8 for 25 year threshold, and 7.4 for 30 year threshold after covariate adjustment), heritability estimates for these phenotypes were also calculated under the $t$ distribution, which is less sensitive to the effects of kurtosis. Significant heritability values were ob- 
Table 2. Narrow sense heritability estimates for $378 \mathrm{PI} \mathrm{ZZ} \mathrm{subjects} \mathrm{including} \mathrm{and} \mathrm{excluding} \mathrm{ascertainment} \mathrm{correction} \mathrm{and} \mathrm{smoking}$ covariates

\begin{tabular}{lllllr}
\hline $\begin{array}{l}\text { Ascertainment } \\
\text { correction }\end{array}$ & $\begin{array}{l}\text { Smoking } \\
\text { covariates }\end{array}$ & $\begin{array}{l}\text { FEV1 } \\
\text { (pre-bronchodilator) } \\
\text { heritability (p) }\end{array}$ & $\begin{array}{l}\text { FEV1 } \\
\text { (post-bronchodilator) } \\
\text { heritability (p) }\end{array}$ & $\begin{array}{l}\text { FEV1/FVC } \\
\text { (pre-bronchodilator) } \\
\text { heritability (p) }\end{array}$ & $\begin{array}{l}\text { FEV1/FVC } \\
\text { (post-bronchodilator) } \\
\text { heritability (p) }\end{array}$ \\
\hline None & none $^{\mathrm{a}}$ & $0(0.50)$ & $0(0.50)$ & $0(0.50)$ & $0(0.50)$ \\
& yes $^{\mathrm{b}}$ & $0.12 \pm 0.14(0.20)$ & $0.13 \pm 0.16(0.19)$ & $0.22 \pm 0.14(0.05)$ & $0.13 \pm 0.15(0.20)$ \\
Index case & smokers only $^{\mathrm{b}}$ & $0.22 \pm 0.18(0.11)$ & $0.23 \pm 0.22(0.15)$ & $0.16 \pm 0.18(0.18)$ & $0(0.50)$ \\
& none $^{\mathrm{a}}$ & $0(0.50)$ & $0(0.50)$ & $0.06 \pm 0.13(0.32)$ & $0(0.50)$ \\
& yes $^{\mathrm{b}}$ & $0.17 \pm 0.15(0.13)$ & $0.19 \pm 0.16(0.11)$ & $0.32 \pm 0.13(0.008)$ & $0.26 \pm 0.14(0.03)$ \\
& smokers only $^{\mathrm{b}}$ & $0.38 \pm 0.19(0.03)$ & $0.47 \pm 0.21(0.02)$ & $0.24 \pm 0.19(0.10)$ & $0.11 \pm 0.22(0.32)$ \\
\hline
\end{tabular}

${ }^{\text {a }}$ Covariates include age, age ${ }^{2}$, height, height ${ }^{2}$, sex.

${ }^{\mathrm{b}}$ Covariates include age, age ${ }^{2}$, height, height ${ }^{2}$, sex, pack-years, pack-years ${ }^{2}$.

Table 3. Heritability estimates for rate phenotypes for 378 PI ZZ individuals

\begin{tabular}{|c|c|c|c|c|c|}
\hline & \multirow{2}{*}{$\begin{array}{l}\text { Median } \\
\text { (interquartile range) }\end{array}$} & \multicolumn{2}{|c|}{ Normal distribution } & \multicolumn{2}{|l|}{$\mathrm{t}$ distribution } \\
\hline & & heritability $^{\mathrm{a}}$ & $\mathrm{p}$ value & heritability $^{\mathrm{a}}$ & $\mathrm{p}$ value \\
\hline Rate using age of onset as age 20 & $2.40(1.95)$ & $0.55 \pm 0.14$ & $3.1 \times 10^{-5}$ & $0.43 \pm 0.14$ & $1.0 \times 10^{-3}$ \\
\hline Rate using age of onset as age 25 & $3.84(2.44)$ & $0.71 \pm 0.13$ & $1.0 \times 10^{-7}$ & $0.52 \pm 0.14$ & $8.3 \times 10^{-5}$ \\
\hline Rate using age of onset as age 30 & $3.49(3.40)$ & $0.94 \pm 0.13$ & $1.0 \times 10^{-11}$ & $0.64 \pm 0.16$ & $9 \times 10^{-6}$ \\
\hline
\end{tabular}

${ }^{\text {a }}$ Covariates include pack-years, pack-years ${ }^{2}$, and sex.

served for all three severity rate phenotypes. Although heritability estimates were attenuated for all of the age thresholds under the $t$ distribution, the findings of high heritability remained robust (table 3 ).

\section{Discussion}

Severe alpha- 1 antitrypsin deficiency is a proven genetic cause of COPD; individuals homozygous for the $\mathrm{Z}$ deficiency allele are clearly at increased risk for the development of severe, early-onset COPD [Larsson, 1978]. However, the etiology of the variable progression in lung function decline among PI ZZ subjects is poorly understood. Variability for the presence of low spirometric measures of lung function, even after controlling for smoking, has been observed in our current cohort [Demeo et al., 2007b], which echoes prior findings amongst other cohorts of PIZZ individuals [Silverman et al., 1989]. Genetic modeling performed by Silverman and colleagues [Silverman et al., 1990] and our current data sup- port a role for modifier genes in this classic mendelian disease, and suggest that genetic influences on lung function measures are substantial, beyond the effect of the PI locus. In a candidate gene study, we found evidence for association of IL10 variants with airflow obstruction in PI ZZ subjects [Demeo et al., 2007a], but positional candidates from linkage studies have yet to be identified.

Our study represents the largest reported family-based assessment of aggregation of lung function phenotypes in PI ZZ subjects. Although we detected familial aggregation of spirometric measures of COPD, the heritability was most robust for measures of $\mathrm{FEV}_{1}$ in a smokers-only analysis. As $\mathrm{FEV}_{1}$ is an important phenotype for COPD severity, this observation, together with the observation that heritability measure approached zero in a model that excluded smoking, bespeaks the relevance of gene-bysmoking interactions in the pathogenesis and severity of COPD in PI ZZ subjects.

Many past studies of $\mathrm{FEV}_{1}$ and $\mathrm{FEV}_{1} / \mathrm{FVC}$ have suggested that genetic influences are important determinants of spirometric measures in the general population. 
General population estimates for the heritability of spirometric measures have generally fallen between the extreme measures observed in twin studies. Heritability estimates of $\mathrm{FEV}_{1}$ in twin studies have varied from 0 (in non-smoking twins) [Ghio et al., 1989] to 0.77 [Hubert et al., 1982]; with general population estimates for $\mathrm{FEV}_{1}$ generally between 0.26 [Chen et al., 1996] and 0.52 [Wilk et al., 2000]. Our expectation was that familial aggregation of spirometric measures in homozygous PI ZZ individuals would consistently approach the higher end of heritability in the general population due to the increased susceptibility for lower lung function and COPD. However, we observed heritability measures of 0 in models without smoking covariates and marginal to non-significant measures without the inclusion of an ascertainment correction.

The importance of the careful inclusion of smoking as an environmental influence has been demonstrated in two general population-based studies of familial aggregation of lung function decline. In the Tucson Epidemiological Study of Airway Obstructive Diseases, an evaluation of longitudinal lung function measures from 5 to 20 years noted a high correlation for $\mathrm{FEV}_{1}$ decline in smoking concordant siblings $(\mathrm{r}=0.483, \mathrm{p}<0.01)$, while there was no significant correlation between smoking discordant sibling pairs $(r=0.031, p>0.05)$. They concluded that this observation may be secondary to 'genetic susceptibility to an accelerated rate of decline associated with smoking', resulting in increased $\mathrm{FEV}_{1}$ correlation in smoking concordant siblings and a decreased correlation amongst smoking discordant siblings [Kurzius-Spencer et al., 2001]. In the Framingham Heart Study, an increase in heritability of longitudinal decline in $\mathrm{FEV}_{1}$ was observed among smoking-concordant subjects, with heritability of 0.05 for models that included all subjects compared to a heritability of 0.18 in models limited to family members concordant for smoking status [Gottlieb et al., 2001]. In the setting of AAT deficiency, Silverman and colleagues used segregation analysis to provide evidence for an additional major gene influencing $\mathrm{FEV}_{1}$ beyond the PI locus. After removing the effect of pack-years of smoking, evidence for a major gene effect was not observed; this was consistent with the role of a putative gene enhancing the effect of cigarette smoking [Silverman et al., 1990].

In a linkage study in families ascertained on the basis of a proband with severe, early-onset COPD but without AAT deficiency, the inclusion of pack-years of smoking in heritability and linkage models for the whole cohort was used to evaluate the main effect of smoking on the phenotype, while a smokers-only analysis was used to address the potential influence of gene by smoking interactions. In this Boston Early-Onset COPD study, using a smokers-only approach resulted in LOD scores greater than 2 for linkage of spirometric measures of lung function with chromosomes $2,12,16,20$ and 22, suggesting the relevance of gene-by-smoking interactions [DeMeo et al., 2004]. These data from cohorts susceptible to early-onset COPD, together with the observations in general population cohorts, reinforce the findings in our current study that polygenic effects on spirometric measures in AAT deficiency will likely act through gene-bysmoking interactions. The ratio of $\mathrm{FEV}_{1} / \mathrm{FVC}$ is used to determine the presence of COPD, while $\mathrm{FEV}_{1}$ is the spirometric measure used to gauge the severity of COPD. In our analysis we observed significant heritability for $\mathrm{FEV}_{1} / \mathrm{FVC}$ in the models that included pack-years of cigarettes smoked but not for the smokers-only model; conversely for $\mathrm{FEV}_{1}$ we observed no significant heritability in models that considered the main effect of smoking, but we did observe significance of the smokers-only model. One explanation for the model dependence of the statistical significance for the heritabilities for $\mathrm{FEV}_{1}$ and $\mathrm{FEV}_{1} / \mathrm{FVC}$ is that the heritability for susceptibility to COPD (as measured by $\mathrm{FEV}_{1} / \mathrm{FVC}$ ) is captured by the inclusion of the main effect of smoking, whereas the heritability for the severity of COPD as captured by the FEV is better predicted by gene-by-smoking interactions. Although another explanation is that our findings represent false positives, given prior literature supporting the significant heritability of spirometric parameters in the general population and in COPD cohorts, we suspect that this is less likely. Demonstrating the model dependence for the heritability estimates suggests the importance of modeling both the main effect of cigarette smoking and gene-by-smoking interactions in future linkage analyses of AAT deficiency.

Ascertainment bias may either inflate or diminish heritability estimates. In studies of AAT deficiency, ascertainment may be on the basis of lung disease, liver disease, or population screening, each of which may be influenced by different genetic modifiers or gene-by-environment interactions. In our current study, having lung disease was not an inclusion criterion and ascertainment was on the basis of homozygosity for the $\mathrm{Z}$ allele at the PI locus. This uniform ascertainment scheme was used in an attempt to eliminate effects on heritability due to heterogeneity at the PI locus, and is a unique and important feature of our study. To minimize residual ascertainment bias, we used the person first diagnosed in the family (the 
index case) in our ascertainment correction in the variance component models. We observed no significant evidence for heritability of $\mathrm{FEV}_{1}$ or $\mathrm{FEV}_{1} / \mathrm{FVC}$ without the ascertainment correction regardless of covariate inclusion (except a marginal trend for pre-bronchodilator $\mathrm{FEV}_{1} / \mathrm{FVC}$ in a model that included smoking). Our results indicate that ignoring this ascertainment effect limits the detection of genetic modifier influences. This critical role for the ascertainment correction was also observed in a linkage study of 28 AAT deficient families. Using the protease inhibitor type as a genetic marker, Silverman and colleagues [2001] demonstrated no evidence of linkage for $\mathrm{FEV}_{1}$ and $\mathrm{FEV}_{1} / \mathrm{FVC}$ with the PI locus in models that excluded an ascertainment correction; evidence for linkage increased with the inclusion of the appropriate ascertainment correction.

Consideration of additional phenotypes may be required to identify genetic modifiers of AAT deficiency. We have found that severity rate phenotypes, despite the obvious limitations of including only one time point in the estimation, did provide significant evidence for heritability. The magnitude of the heritability estimates of the severity rate phenotypes increased as the age-of-onset of $\mathrm{FEV}_{1}$ decline parameter was increased from 20 to 25 to 30 years of age. One possible explanation is that these findings relate to kurtosis, since the kurtosis increased as the age-of-onset of decline parameter increased. However, these differences remained robust with heritability estimation under the $t$ distribution, making this explanation less likely. A biologically relevant explanation for these findings is that the severity rate phenotype values for young subjects with severe reductions in $\mathrm{FEV}_{1}$ are amplified using a higher age-of-onset threshold; such individuals may be more likely to carry deleterious modifier genes-potentially leading to higher heritability estimates in this study population. These severity rate phenotypes may capture age-of-onset effects relevant to susceptibility to accelerated decline in lung function and to the development COPD, suggesting that age-of-onset for lower lung function and potentially lung function decline may be under genetic control in individuals with AAT deficiency. Thus, these severity rate phenotypes should be considered in future AAT genetic modifier studies. Future studies might also benefit from consideration of CT imaging phenotypes, which may capture heritable features of early-onset lung disease (such as emphysema) that are inadequately measured by spirometry.

Although the subjects included in this study demonstrate a wide range of lung function measures for the index and non-index cases, our study may be biased in that individuals needed to have at least one living PI ZZ sibling to be included in the study. By dint of these inclusion criteria, families with the most severe disease (and thus potentially modifier genes predictive of a more severe disease course) may not have more than one surviving PI $\mathrm{ZZ}$ individual and thus would not be included in this study. This may have led to an underestimate of the heritability of lung function measures, as many of the families included in our study have index proband-siblings pairs with highly discordant spirometric measures. Although variation in measurement of spirometric phenotypes is always an important concern, the same spirometry equipment and testing techniques were utilized at all centers for all subjects, as previously described [Demeo et al., 2007b]. Beyond personal reports of pack-years of smoking and smoking status, we did not assess any other potentially shared household/environmental effects, especially passive smoke exposure, which may contribute to lung function; as well, we do not have longitudinal spirometric measures. Lastly, we did not include the use of AAT augmentation therapy in our final variance component models, as regression modeling suggested a negative effect on lung function (data not shown), which likely represented confounding by indication.

Many studies have demonstrated the important role for genetic contributions to spirometric measures of lung function in healthy individuals. A high heritability for $\mathrm{FEV}_{1}$ has also been demonstrated in cystic fibrosis [Vanscoy et al., 2007], like AAT deficiency a monogenic autosomal recessive disorder. The cumulative evidence in individuals at risk for COPD suggests not only a heritable component to lung function, but also the importance of gene-by-smoking interactions in the investigation of variable expression of lung function deficits and susceptibility to COPD. Modifier genes probably explain some of the variable manifestations of lung disease in those with AAT deficiency, but their identification will be challenging. To date, no large linkage studies have been reported to identify key genomic regions likely harboring susceptibility genes for AAT deficiency. Careful modeling of gene-by-smoking interactions in linkage models will be a crucial next step for identifying additional genes associated with early-onset COPD in AAT deficiency.

\section{Acknowledgement}

We thank Dr. Thomas L. Croxton for helpful suggestions regarding alternative phenotypic measures. 


\section{References}

Standardization of Spirometry, 1994 Update. American Thoracic Society. Am J Respir Crit Care Med 1995;152:1107-1136.

-Almasy L, Blangero J: Multipoint quantitativetrait linkage analysis in general pedigrees. Am J Hum Genet 1998;62:1198-1211.

Bernspang E, Sveger T, Piitulainen E: Respiratory symptoms and lung function in 30year-old individuals with alpha-1-antitrypsin deficiency. Respir Med 2007;101:19711976.

Chen Y, Horne SL, Rennie DC, Dosman JA: Segregation analysis of two lung function indices in a random sample of young families: the Humboldt Family Study. Genet Epidemiol 1996;13:35-47.

Crapo RO, Morris AH, Gardner RM: Reference spirometric values using techniques and equipment that meet ATS recommendations. Am Rev Respir Dis 1981;123:659664.

- DeMeo DL, Campbell EJ, Barker AF, Brantly ML, Eden E, McElvaney NG, Rennard SI, Sandhaus RA, Stocks JM, Stoller JK, et al: IL10 polymorphisms are associated with airflow obstruction in severe alpha-1 antitrypsin deficiency. Am J Respir Cell Mol Biol 2008;38:114-120.

-DeMeo DL, Celedon JC, Lange C, Reilly JJ, Chapman HA, Sylvia JS, Speizer FE, Weiss ST, Silverman EK: Genome-wide linkage of forced mid-expiratory flow in chronic obstructive pulmonary disease. Am J Respir Crit Care Med 2004;170:1294-1301.
Demeo DL, Sandhaus RA, Barker AF, Brantly ML, Eden E, McElvaney NG, Rennard S, Burchard E, Stocks JM, Stoller JK, et al: Determinants of airflow obstruction in severe alpha-1-antitrypsin deficiency. Thorax 2007b;62:805-812.

Ghio AJ, Crapo RO, Elliott CG, Adams TD, Hunt SC, Jensen RL, Fisher AG, Afman GH: Heritability estimates of pulmonary function. Chest 1989;96:743-746.

Gottlieb DJ, Wilk JB, Harmon M, Evans JC, Joost O, Levy D, O’Connor GT, Myers RH: Heritability of longitudinal change in lung function. The Framingham study. Am J Respir Crit Care Med 2001;164:1655-1659.

-Hubert HB, Fabsitz RR, Feinleib M, Gwinn C: Genetic and environmental influences on pulmonary function in adult twins. Am Rev Respir Dis 1982;125:409-415.

Kurzius-Spencer M, Sherrill DL, Holberg CJ, Martinez FD, Lebowitz MD: Familial correlation in the decline of forced expiratory volume in one second. Am J Respir Crit Care Med 2001;164:1261-1265.

Larsson C: Natural history and life expectancy in severe alpha1-antitrypsin deficiency, Pi Z. Acta Med Scand 1978;204:345-351.

- Seersholm N, Kok-Jensen A, Dirksen A: Decline in FEV1 among patients with severe hereditary alpha-1 antitrypsin deficiency type PiZ. Am J Respir Crit Care Med 1995;152(6 Pt 1):1922-1925.
-Silverman EK, Mosley JD, Rao DC, Palmer LJ, Province MA, Elston RC, Weiss ST, Campbell EJ: Linkage analysis of Alpha-1 antitrypsin deficiency: Lessons for complex diseases. Hum Hered 2001;52:223-232.

- Silverman EK, Palmer LJ, Mosley JD, Barth M, Senter JM, Brown A, Drazen JM, Kwiatkowski DJ, Chapman HA, Campbell EJ, et al: Genomewide linkage analysis of quantitative spirometric phenotypes in severe early-onset chronic obstructive pulmonary disease. Am J Hum Genet 2002;70:1229-1239.

Silverman EK, Pierce JA, Province MA, Rao DC, Campbell EJ: Variability of pulmonary function in alpha-1-antitrypsin deficiency: clinical correlates. Ann Intern Med 1989;111: 982-991.

-Silverman EK, Province MA, Campbell EJ, Pierce JA, Rao DC: Variability of pulmonary function in alpha-1-antitrypsin deficiency: residual family resemblance beyond the effect of the Pi locus. Hum Hered 1990;40: 340-355.

-Vanscoy LL, Blackman SM, Collaco JM, Bowers A, Lai T, Naughton K, Algire M, McWilliams R, Beck S, Hoover-Fong J, et al: Heritability of lung disease severity in cystic fibrosis. Am J Respir Crit Care Med 2007;175:1036-1043.

-Wilk JB, Djousse L, Arnett DK, Rich SS, Province MA, Hunt SC, Crapo RO, Higgins M, Myers RH: Evidence for major genes influencing pulmonary function in the NHLBI Family Heart Study. Genet Epidemiol 2000; 19:81-94. 